\title{
Zoneamento bioclimático para a raça ovina Dorper no Estado de Pernambuco
}

\author{
Aline Medeiros de Paula Mendes ${ }^{(1)}$, Marcílio de Azevedo(1), Pabrício Marcos Oliveira Lopes ${ }^{(2)}$ \\ e Geber Barbosa de Albuquerque Moura(2)
}

\begin{abstract}
(1) Universidade Federal Rural de Pernambuco (UFRPE), Departamento de Zootecnia, Avenida Dom Manoel de Medeiros, s/no, CEP 52171-900 Recife, PE, Brasil. E-mail: amdpmendes@gmail.com, marcilio@dz.ufrpe.br (2)UFRPE, Departamento de Agronomia, CEP 52171-900 Recife, PE, Brasil. E-mail: pabricio@depa.ufrpe.br, geber@depa.ufrpe.br
\end{abstract}

Resumo - O objetivo deste trabalho foi realizar o zoneamento bioclimático para ovinos da raça Dorper, no Estado de Pernambuco. Foram utilizados dados meteorológicos médios diários de 246 postos meteorológicos no estado. As variáveis temperatura do ar e umidade relativa do ar foram utilizadas para o cálculo do índice de temperatura e umidade. Com os valores destas variáveis, traçaram-se as isolinhas por meio do programa Surfer. A região do Agreste pernanbucano apresenta melhores condições climáticas para a raça Dorper, durante todo o ano, do que a região que compreende o litoral, a Zona da Mata e o Semiárido. Nos meses mais quentes e nas regiões mais críticas, como o Sertão, é necessária a implementação de manejo, como o provimento de sombra, para amenizar o estresse pelo calor e não comprometer o desempenho produtivo da raça.

Termos para indexação: índice de temperatura e umidade, ovinocultura, temperatura do ar, umidade relativa do ar.

\section{Bioclimatic zoning for Dorper sheep in the state of Pernambuco, Brazil}

\begin{abstract}
The objective of this work was to perform the bioclimatic zoning for Dorper sheep, in the state of Pernambuco, Brazil. Average daily meteorological data from 246 meteorological stations in the state were used. The variables air temperature and air relative humidity were used to calculate the temperature and humidity index. With the values of these variables, isolines were traced using the Surfer software. The Agreste region of Pernambuco shows the best weather conditions for Dorper breed throughout the year than the region comprising the coast, "Zona da Mata", and "Semiárido". In the warmer months and in critical regions, as the "Sertão", the implementation of management is required, to provide shade to mitigate heat stress and not compromise the productive performance of the breed.
\end{abstract}

Index terms: temperature and humidity index, sheep production, air temperature, air relative humidity.

\section{Introdução}

Altas temperaturas do ar, principalmente quando associadas à umidade elevada e à radiação solar direta, são os principais elementos meteorológicos responsáveis pelo baixo desempenho animal. A interação animal-clima deve ser considerada quando se busca maior eficiência na exploração pecuária, pois, as diferentes respostas fisiológicas do animal às peculiaridades de cada região são determinantes no sucesso da atividade (Navarini et al., 2009). A interferência da temperatura e da umidade do ar no conforto térmico dos ovinos afeta o desempenho produtivo e a própria sobrevivência destes. Assim, na introdução de determinada raça a uma região é importante avaliar se o tipo de clima é semelhante ao da região de origem do animal (Pires et al., 2003). A seleção de animais que melhor se adaptam ao sistema de produção, inclusive ao estresse pelo calor, ainda é necessária, para permitir a sustentabilidade dos sistemas de produção em climas mais quentes (Scholtz et al., 2013).

O Nordeste brasileiro apresenta um clima complexo; consequentemente, é possível encontrar nessa região algumas mesorregiões geográficas muito particulares, cujos climas vão do superúmido das zonas litorâneas ao clima seco do sertão, na região conhecida como o Semiárido Nordestino. O Semiárido é um conjunto de espaços que se caracterizam pelo balanço hídrico negativo resultante das precipitações médias anuais 
inferiores a $800 \mathrm{~mm}$, pela insolação média de 2.800 horas por ano, temperaturas médias anuais de $23^{\circ} \mathrm{C}$ a $27^{\circ} \mathrm{C}$, evaporação de $2.000 \mathrm{~mm}$ por ano e umidade relativa do ar média em torno de $50 \%$ (Brito et al., 2007).

$\mathrm{Na}$ ovinocultura nordestina, em geral, predominam animais nativos, sem padrão racial definido, que apresentam excelente adaptabilidade às condições de calor da região. Não obstante, apresentam baixos níveis de produtividade. Assim, entre os criadores da região, tem sido prática comum a introdução de genótipos exóticos, para cruzamento com as raças naturalizadas ou mesmo a criação em rebanhos puros. No entanto, essa introdução é realizada sem estudos prévios, seja sobre a adaptabilidade dos animais às condições ambientais adversas da região, notadamente o calor, seja sobre regiões bioclimáticas mais favoráveis ao seu desempenho. Nesse sentido, tem-se observado a preferência dos criadores pela introdução de ovinos da raça Dorper. Essa raça surgiu na África do Sul, na década de 40, e é resultante do cruzamento entre as raças Dorset Horn, de grande capacidade para produção de carne, e a Black Head Persian, conhecida por sua rusticidade, conforme Milne (2000). Este autor relata que ovinos Dorper produzem de maneira satisfatória, nas condições áridas e semiáridas da África do Sul, e sua alta rusticidade e adaptabilidade são pontos positivos que estimulam a exportação para outros países; é considerada uma raça de boa adaptabilidade, capaz de manter níveis aceitáveis de produção sob ampla variedade de condições ambientais.

Alguns poucos trabalhos realizados no Brasil mostram que os ovinos Dorper apresentam adaptabilidade mediana ao calor nordestino (Bezerra et al., 2011), o que indicaria a necessidade de mais estudos, para avaliar seu bom desempenho em ambientes adversos, sobretudo no Semiárido Nordestino. A crescente introdução de ovinos Dorper, aliada aos reduzidos estudos sobre a adaptabilidade dos animais ao ambiente físico nordestino, destaca a importância da realização de um zoneamento bioclimatológico para animais desta raça no Estado de Pernambuco.

O zoneamento bioclimático, por meio do monitoramento das condições climáticas, permite a previsão de áreas com probabilidade de ocorrência do estresse calórico, que pode ser aferido por meio de uma série de variáveis, como: temperatura retal, frequência respiratória, ingestão de água, produção de leite, reprodução, comportamento de ruminação e ócio
(Pires et al., 2003). O zoneamento auxilia a tomada de decisões quanto ao manejo ambiental, para minimizar o estresse pelo calor, tais como o sombreamento para animais não confinados, nos horários mais quentes do dia, o que, segundo Couto et al. (2009), pode reduzir a frequência respiratória e melhorar o desempenho produtivo de ovinos. Em condições ambientais termicamente desconfortáveis, os ovinos tendem a reduzir consideravelmente o consumo de matéria seca, na tentativa de diminuir a taxa metabólica e a consequente produção de calor metabólico.

O objetivo deste trabalho foi realizar um zoneamento bioclimático para ovinos da raça Dorper, no Estado de Pernambuco.

\section{Material e Métodos}

Elaborou-se um banco de dados, a partir de valores das normais mensais de temperatura mínima, máxima e média, umidade relativa do ar e precipitação pluvial do período de 1961 a 1990 (Dados pluviométricos mensais do Nordeste, 1990; Normais climatológicas do Brasil, 2009). Esse banco contém valores de temperatura e umidade relativa do ar, observados por oito estações meteorológicas convencionais, pertencentes ao Instituto Nacional de Meteorologia, e estimados em 238 localidades do Estado de Pernambuco. Os valores normais mensais de temperatura do ar foram estimados por meio das coordenadas geográficas (latitude, longitude e altitude) dos locais de interesse como entradas no programa computacional Estima T, descrito por Cavalcanti et al. (2006) e disponível na Unidade Acadêmica de Ciências da Atmosfera, da Universidade Federal de Campina Grande. As coordenadas geográficas e as precipitações pluviais de 146 postos pluviômetros da Sudene (Dados pluviométricos mensais do Nordeste, 1990) foram utilizadas como entrada no modelo multiplicativo, para estimação dos valores normais mensais de umidade relativa do ar. Segundo Silva (2006), esse modelo - para duas funções e escrito para estimativa da umidade relativa do ar (UR) - é dado pela expressão $U R=f(x) f(y)$, em que: a função $\mathrm{f}(\mathrm{x})$ depende do índice efetivo de umidade $(\mathrm{Im}$, adimensional $)(\mathrm{Im}=\{[\mathrm{P} / \mathrm{ETP}]\} \times 100)$, em que a precipitação pluvial ( $\mathrm{P}, \mathrm{mm})$ e a evapotranspiração potencial (ETP, mm) são necessárias; e a segunda função $\mathrm{f}(\mathrm{y})$ serve para isolar a variabilidade dos valores normais mensais de UR, dada por 
$\mathrm{f}(\mathrm{y})=\mathrm{URo} / \mathrm{f}(\mathrm{x})$, em que URo é a umidade relativa do ar observada.

Para facilitar o zoneamento bioclimático, o Estado de Pernambuco foi dividido nas seguintes zonas fisiográficas: zona bioclimática I, refere-se ao litoral e Zona da Mata; zona bioclimática II, Agreste; e zona bioclimática III, Sertão. Foram elaborados mapas com temperaturas do ar $\left(\mathrm{Ta},{ }^{\circ} \mathrm{C}\right)$, umidade relativa (UR, \%) e índice de temperatura e umidade (ITU) do mês mais quente e do mês mais frio do ano, janeiro e junho, respectivamente, com base nas temperaturas médias compensadas desses meses (Tabela 1).

$\mathrm{O}$ índice de temperatura e umidade foi calculado pela equação ITU $=\mathrm{Ta}+0,36 \mathrm{td}+41,5$, proposta por Thom (1958), em que: td é a temperatura do ponto de orvalho $\left({ }^{\circ} \mathrm{C}\right)$, calculada em função da pressão real do vapor d'água (e, hPa) e expressa por Vianello \& Alves (2012) como:

$$
\mathrm{t}_{\mathrm{d}}=186,4905-237,3 \times \log _{10}^{\mathrm{e}} / \log _{10}^{\mathrm{e}}-8,2859
$$

Esse índice foi avaliado por meio dos limites críticos estabelecidos para ovinos da raça Dorper, obtidos por Mendes (2014) no Estado de Pernambuco, ou seja, 79,5 para a elevação da temperatura retal e 72,8 para a frequência respiratória.

O mapa vetorial do contorno do Estado de Pernambuco usado como "máscara" foi obtido por meio do banco Atlas, do Spring/Inpe - Sistema de Informações Geográficas, Instituto Nacional de Pesquisas Espaciais (www.dpi.inpe.br/spring/). Para a plotagem do contorno do Estado, a interpolação dos dados foi feita pelo método de krigagem ordinária (Castro et al., 2010) e gerada no programa Surfer, versão demo 10.0 (Golden Software, Golden, CO, USA).

Tabela 1. Valores máximos e mínimos de temperatura do ar, umidade relativa do ar e índice de temperatura e umidade, para os meses de janeiro e junho, de 1961 a 1990.

\begin{tabular}{lcc}
\hline Variável & \multicolumn{2}{c}{ Meses } \\
\cline { 2 - 3 } & Janeiro & Junho \\
\hline Temperatura mínima $\left({ }^{\circ} \mathrm{C}\right)$ & 21,6 & 18,7 \\
Temperatura máxima $\left({ }^{\circ} \mathrm{C}\right)$ & 27,9 & 24,5 \\
Umidade relativa mínima (\%) & 53,0 & 50,8 \\
Umidade relativa máxima (\%) & 77,0 & 92,8 \\
Índice de temperatura e umidade - mínimo & 68,5 & 66,3 \\
Índice de temperatura e umidade - máximo & 76,2 & 73,8 \\
\hline
\end{tabular}

Pesq. agropec. bras., Brasília, v.49, n.12, p.986-993, dez. 2014 DOI: 10.1590/S0100-204X2014001200009

\section{Resultados e Discussão}

No mês de janeiro, as temperaturas variaram de 21,5 a $28^{\circ} \mathrm{C}$ e, em junho, de 18,5 a $24,5^{\circ} \mathrm{C}$ (Figuras 1 e 2 ). Verificou-se que a temperatura diminuiu da Zona da Mata (zona bioclimática I) à região do Agreste (zona bioclimática II) do Estado, e aumentou no sentido do Sertão pernambucano (zona bioclimática III).

Nos meses mais quentes e mais frios do ano, a temperatura média não ultrapassou o limite crítico da zona de conforto térmico $\left(30^{\circ} \mathrm{C}\right)$ para ovinos, citada por Hahn (1985). Vale salientar que esta temperatura crítica refere-se a ovinos tosquiados, de regiões de clima temperado. Para ovinos de regiões tropicais e semiáridas, espera-se que este limite seja maior, em razão da maior adaptabilidade ao calor (Neves et al., 2009).

Na zona bioclimática I, que compreende o litoral e a Zona da Mata do Estado, ocorrem altas temperaturas, associadas à elevada umidade relativa do ar. Além de acarretar mudanças comportamentais aos animais (Medeiros et al., 2008), a ação conjunta desses elementos climáticos também desencadeia redução da ingestão e da eficiência alimentar (West, 2003), do crescimento, da reprodução, e da produção de leite (Collier et al., 2006), além de alterações hematológicas (Roberto et al., 2010) e alterações aguda e crônica das concentrações plasmáticas de cortisol e dos hormônios tireoideanos (Starling et al., 2005). Assim, essas regiões não são adequadas à criação de ovinos da raça Dorper. Esses resultados foram semelhantes àqueles encontrados por Barbosa et al. (1995), em estudo de zoneamento bioclimático nos estados do Paraná e São Paulo, para as raças Ideal, Suffolk e Corriedale, que também não são recomendadas para a criação em ambientes onde prevalecem altas temperaturas do ar associadas à umidade elevada. Estes autores verificaram que a distribuição daquelas raças estava associada principalmente às condições de temperatura e umidade das regiões de estudo. Também Barbosa et al. (2001) concluíram que a zona costeira do Estado do Paraná por apresentar altas temperaturas e elevada umidade ao longo do ano - não constitui ambiente adequado para as raças Hampshire Down, Ile-de-France e Texel.

A zona bioclimática II, representada pela região do Agreste, apresentou as condições ideais de temperatura e umidade durante todo o ano, o que favorece o conforto térmico para ovinos da raça Dorper. Essa zona abrange municípios como Pesqueira, Garanhuns, São João, 
Capoeiras, São Bento do Una e Bom Conselho, entre outros. Nessas localidades, a temperatura média variou de 21,0 a $23,5^{\circ} \mathrm{C}$ (Figura 1), faixa considerada por Hahn (1985) como ótima para o desempenho de ovelhas tosquiadas. A raça Dorper é semelhante à raça britânica Suffolk, direcionada para a produção de carne. Barbosa et al. (1995) citam que raças de carne requerem regiões mais frias e úmidas. Do ponto de vista climático, o Agreste é uma região considerada intermediária entre as áreas de clima úmido (Zona da Mata) e de clima seco (Sertão) e apresenta características ora de uma, ora de outra. Assim, nas áreas mais próximas ao sertão (trechos superior e parte do médio), o clima é quente e seco, e o período mais chuvoso vai de fevereiro a junho (chuvas de verão e outono); no trecho submédio (mais próximo da Zona da Mata), a estação chuvosa se estende de março a julho (chuvas de outono e inverno), conforme a Agência Estadual de Planejamento e Pesquisas de Pernambuco (2005). As temperaturas são mais amenas $\left(21,0\right.$ a $\left.25,0^{\circ} \mathrm{C}\right)$, principalmente nos municípios situados no Planalto da Borborema, em razão da maior altitude desses locais. A umidade do ar dificilmente ultrapassa $70 \%$ no verão. Assim, o baixo índice de temperatura e umidade encontrado nessas regiões se situa abaixo do nível crítico, para os ovinos da raça Dorper durante todo o ano.

A zona bioclimática III localiza-se na região semiárida pernambucana (sertão), onde ocorrem altas
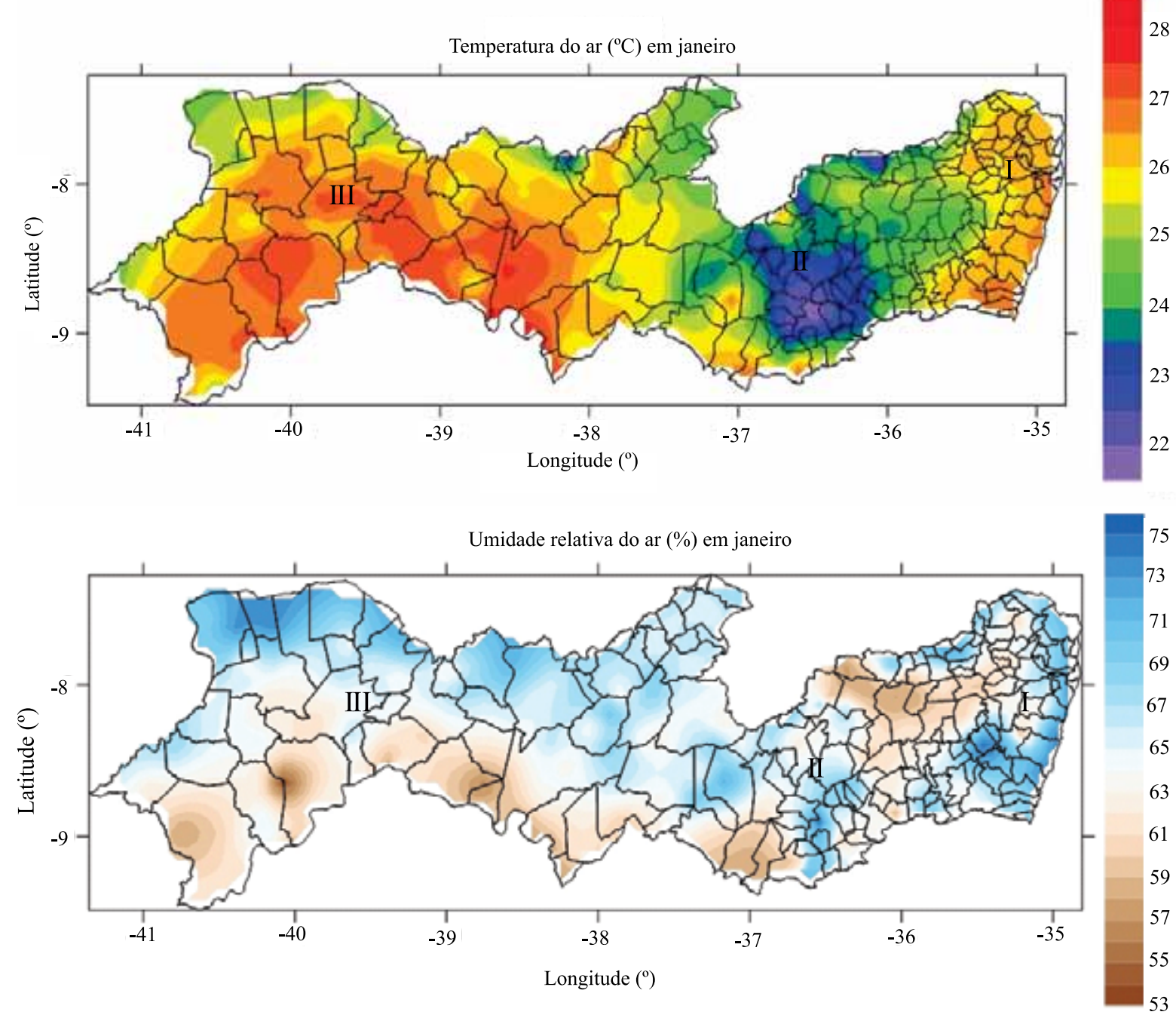

Figura 1. Temperatura do ar e umidade relativa do ar, para janeiro, no período de 1961 a 1990, Estado de Pernambuco. Zona bioclimática I, litoral e Zona da Mata; zona bioclimática II, Agreste; zona bioclimática III, Sertão. 
temperaturas e baixa umidade do ar, que se caracteriza como região quente e seca e, portanto, mais adequada a raças ovinas produtoras de lã (Barbosa et al., 2001). A insolação é alta em virtude da baixa nebulosidade. Apesar das elevadas temperaturas do ar durante o dia, a grande amplitude térmica encontrada nessa região permite a ocorrência de temperaturas mais amenas durante o período noturno.

No mês de janeiro, a zona bioclimática I (Litoral e Zona da Mata) e a III (Sertão) apresentaram variação no ITU de 73,5 a 76,5 e, na zona II (Agreste), houve variação de 68,5 a 73 (Figura 3). De acordo com Mendes (2014), em ambientes com ITU acima de
79,5 os animais se tornariam hipertérmicos, enquanto condições ambientais com valores de ITU acima de 72,8 ocasionariam movimentos respiratórios nos ovinos acima da média obtida para a raça. Nas três zonas bioclimáticas, o ITU ficou abaixo do valor crítico $(79,5)$ estimado para a raça Dorper, ao se considerar como base a temperatura retal, o que caracterizaria conforto térmico em qualquer zona fisiográfica do Estado de Pernambuco. Porém, ao considerar o valor crítico de ITU, em relação à frequência respiratória dos animais, de 72,8, apenas a zona bioclimática II apresentou melhores condições de conforto térmico. Esses baixos valores de ITU, encontrados na zona bioclimática II,
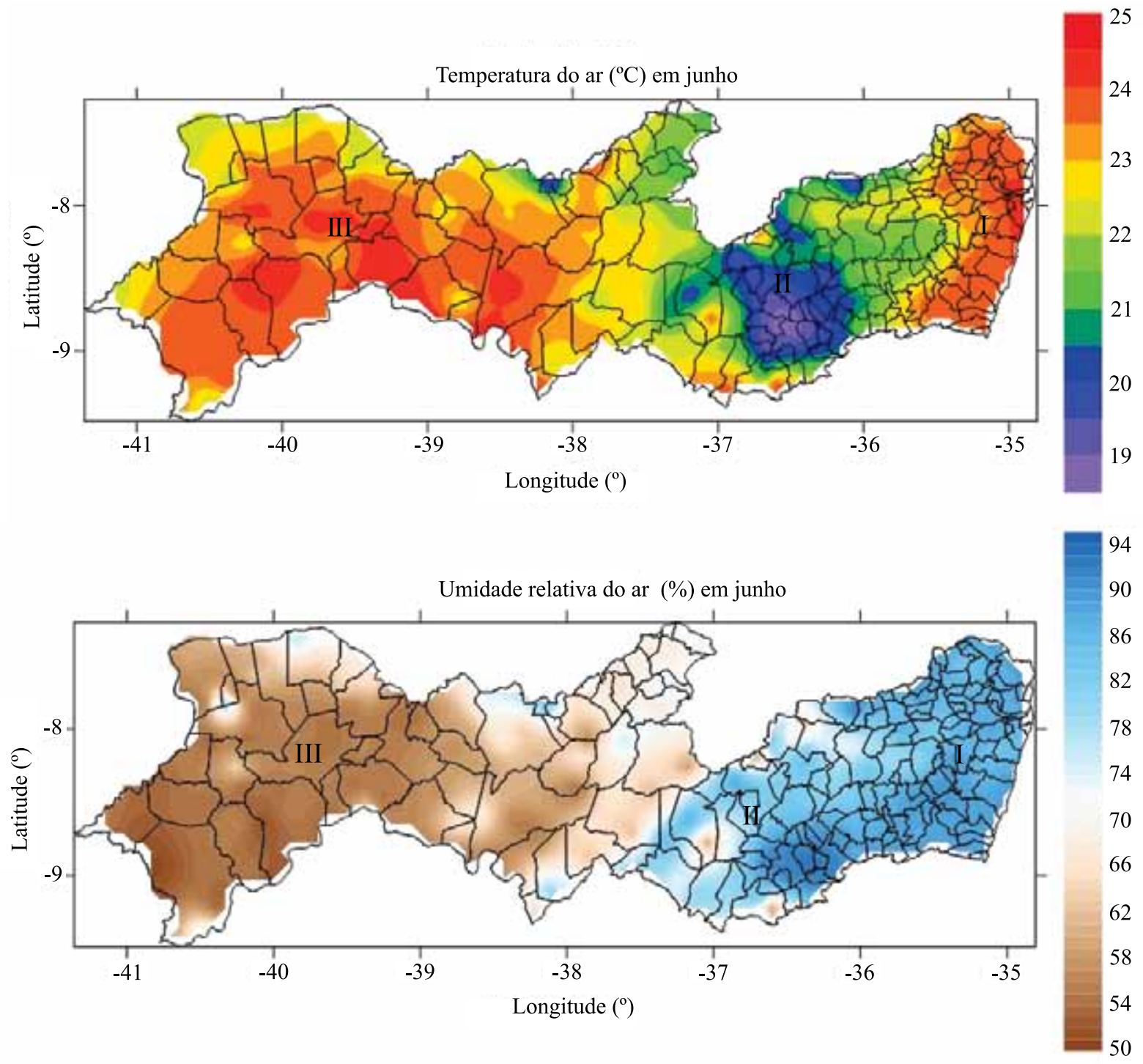

Figura 2. Temperatura do ar e umidade relativa do ar, para junho, no período de 1961 a 1990, Estado de Pernambuco. Zona bioclimática I, litoral e Zona da Mata; zona bioclimática II, Agreste; zona bioclimática III, Sertão. 
provêm da associação de temperaturas ambientais amenas com umidade relativa de 59 a $71 \%$ e propiciam, portanto, condições muito boas para o desempenho dos ovinos da raça Dorper. Nessas condições de ITU, o animal se encontra na zona de conforto térmico e não necessita acionar com intensidade seus mecanismos de termorregulação, o que poderia comprometer sua produção e eficiência reprodutiva (Hahn, 1985). Esses resultados são similares aos encontrados por Barbosa et al. (2001), em estudo de zoneamento bioclimático no Paraná, para as raças ovinas de carne Hampshire Down, Texel e Ile-de-France.
No mês de junho, quando a temperatura do ar variou entre 18,5 e $24,5^{\circ} \mathrm{C}$ e a umidade relativa do ar entre 50 e $94 \%$, sendo considerado o mês mais frio do ano, o ITU apresentou uma faixa de variação de 66 a 74 (Figura 4). Na zona bioclimática I, o ITU variou de 71 a 74, e a umidade foi muito elevada em razão da maior precipitação pluvial nesse mês; assim, como já citado anteriormente, esta não é uma zona adequada para a criação de ovinos de nenhuma raça, tendo em vista a associação de altas temperaturas com umidade elevada durante grande parte do ano, conforme citado por Barbosa et al. (2001). Nessa zona bioclimática, a

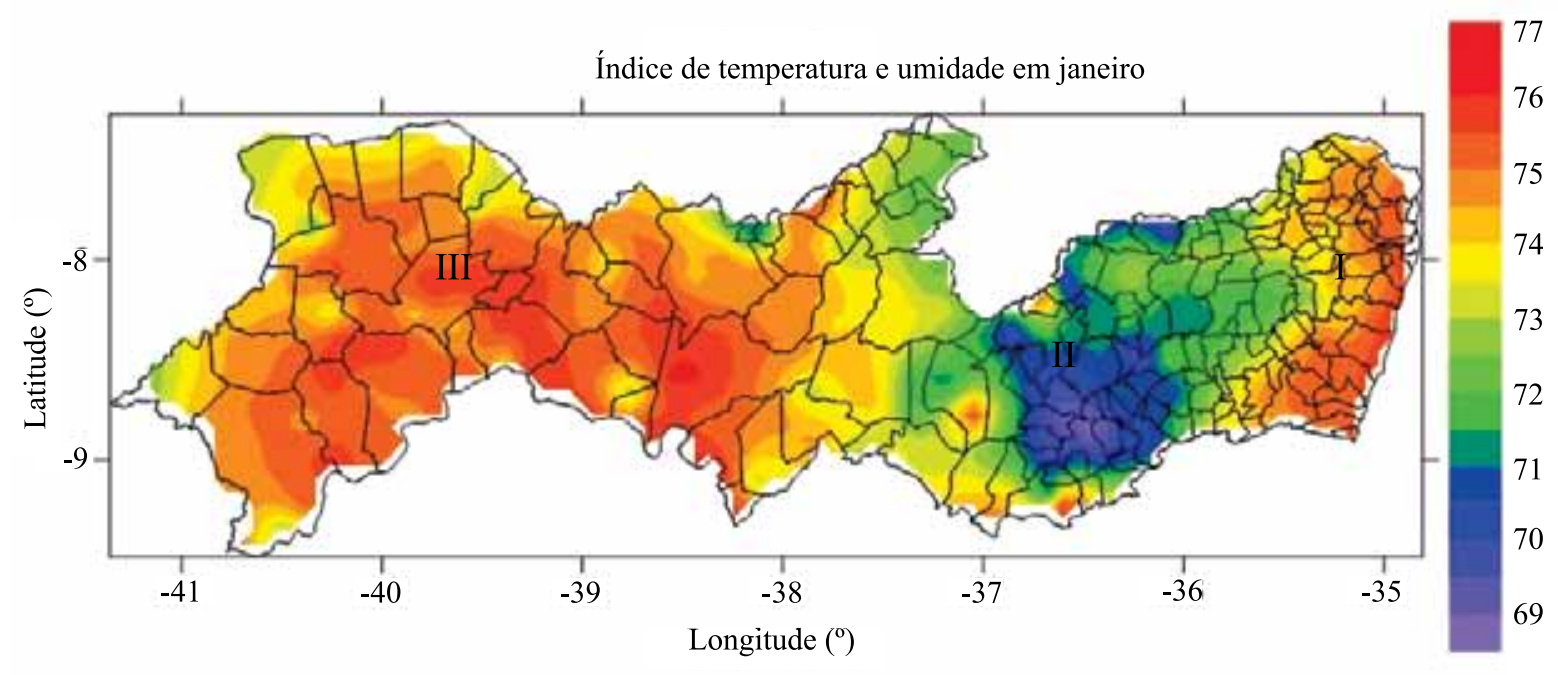

Figura 3. Índice de temperatura e umidade (ITU), para janeiro, no período de 1961 a 1990, Estado de Pernambuco. Zona bioclimática I, litoral e Zona da Mata; zona bioclimática II, Agreste; zona bioclimática III. Sertão.

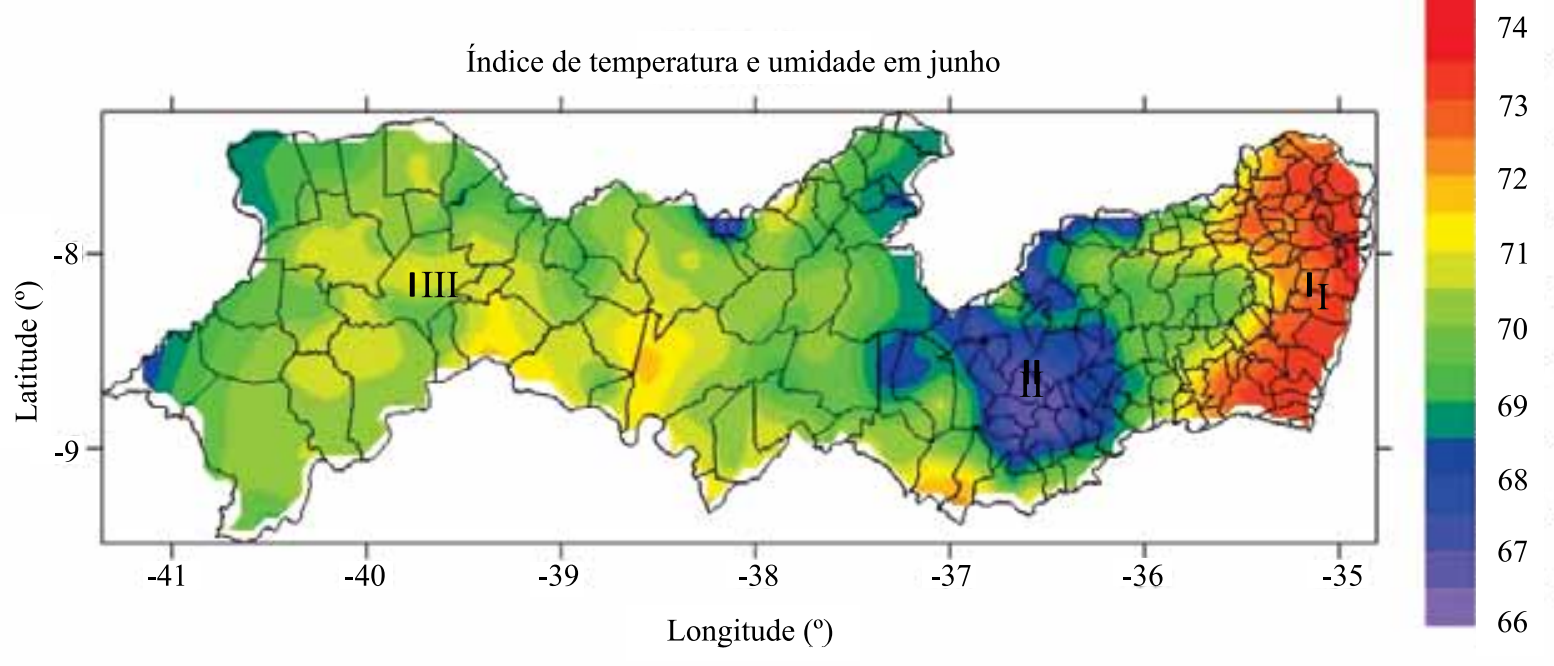

Figura 4. Índice de temperatura e umidade (ITU), para junho, no período de 1961 a 1990, Estado de Pernambuco. Zona bioclimática I, litoral e Zona da Mata; zona bioclimática II, Agreste; zona bioclimática III, Sertão. 
variação observada de ITU superou o valor crítico de 72,8 , observado para a raça Dorper. Isso significa que, nos municípios situados nessa zona, os animais iriam apresentar frequência respiratória acima da média da raça, na tentativa de dissipar o calor corporal excedente. A utilização intensiva desse mecanismo homeostático, em períodos curtos, não tem maiores consequências; entretanto, em períodos mais prolongados, conforme citado por Silva (2008), inibe o consumo de alimentos e a ruminação e pode ocasionar alcalose respiratória.

Na zona bioclimática II, o IT variou de 66 a 71 e, na zona bioclimática III, de 69 a 70,5. Ao se considerar o valor crítico $(79,5)$ de ITU estimado para a raça, com base na temperatura retal, as três zonas oferecem condições adequadas para a criação de ovinos da raça Dorper; mas, ao se considerar o valor estimado com base na frequência respiratória $(72,8)$, as zonas bioclimáticas II e III ofereceram as melhores condições de conforto térmico durante o mês de junho. A zona bioclimática III abrange os sertões do Pajeú, Moxotó e São Francisco e apresenta extensas áreas climáticas homogêneas. Apesar da variação de ITU, no mês de junho, ter-se situado abaixo do valor crítico de ITU para os ovinos Dorper, a variação de umidade relativa que gerou esses baixos índices de ITU mostra que a zona bioclimática III é também muito seca nesse mês, o que favorece mais as raças de ovinos produtoras de lã do que as de carne como a Dorper. Os ambientes quentes e secos são favoráveis à criação de ovinos lanados, uma vez que o velo fino e denso representa barreira à transmissão de calor para a superfície corporal do animal (Silva, 2008).

Vale ressaltar que o zoneamento foi realizado considerando-se estritamente o conforto térmico dos ovinos da raça Dorper, com delimitação das zonas onde os animais poderiam sercriados sem maiores problemas, à semelhança do que foi citado por Barbosa et al. (2001). Entretanto, outros fatores do ambiente, como qualidade das pastagens, são também condicionantes e precisam ser considerados, principalmente na zona bioclimática III, sujeita à ocorrência de secas periódicas, as quais, não raro, atingem os municípios da zona bioclimática II (Agreste).

Em geral, o zoneamento bioclimático para a raça ovina Dorper, no Estado de Pernambuco, permitiu conhecer as regiões que podem proporcionar melhor conforto térmico e, consequentemente, maior produtividade desta raça.

\section{Conclusão}

A região do Agreste do Estado de Pernambuco tem condições mais favoráveis ao conforto climático de ovinos da raça Dorper do que a Zona da Mata e o Sertão.

\section{Agradecimentos}

À Fundação de Amparo à Ciência e Tecnologia do Estado de Pernambuco (Facepe), pela concessão de bolsa.

\section{Referências}

AGÊNCIA ESTADUAL DE PLANEJAMENTO E PESQUISAS DE PERNAMBUCO. Bacia hidrográfica do Rio Ipojuca. Recife: Condepe/Fidem, 2005. 64p. (Série bacias hidrográficas de Pernambuco, 1). Disponível em: <http://www.condepefidem. pe.gov.br/c/document_library/get_file?p_1_id=78673\&folderId=1 41869\&name=DLFE-12005.pdf $>$. Acesso em: 20 set. 2014.

BARBOSA, O.R.; MACEDO, F. de A.F. de; VAN DE GROES, R.; GUEDES, J.M.F. Zoneamento bioclimático da ovinocultura no Estado do Paraná. Revista Brasileira de Zootecnia, v.30, p.454-460, 2001. DOI: 10.1590/S1516-35982001000200023.

BARBOSA, O.R.; SILVA, R.G. da; SCOLAR, J.; GUEDES, J.M.F. Utilização de um índice de conforto térmico em zoneamento bioclimático da ovinocultura. Boletim de Indústria Animal, v.52, p.37-57, 1995.

BEZERRA, W.M. de A.X.; SOUZA, B.B. de; SOUSA, W.H. de; CUNHA, M. das G.G.; BENICIO, T.M.A. Comportamento fisiológico de diferentes grupos genéticos de ovinos criados no Semiárido paraibano. Revista Caatinga, v.24, p.130-136, 2011.

BRITO, L.T. de L.; MOURA, M.S.B. de; GAMA, G.F.B. Potencialidades da água de chuva no Semi-árido brasileiro. Petrolina: Embrapa Semi-Árido, 2007. 181p.

CASTRO, F. da S.; PEZZOPANE, J.E.M.; CECÍLIO, R.A.; PEZZOPANE, J.R.M.; XAVIER, A.C. Avaliação do desempenho dos diferentes métodos de interpoladores para parâmetros do balanço hídrico climatológico. Revista Brasileira de Engenharia Agrícola e Ambiental, v.14, p.871-880, 2010. DOI: 10.1590/ S1415-43662010000800012.

CAVALCANTI, E.P.; SILVA, V. de P.R.; SOUSA, F. de A.S. de. Programa computacional para a estimativa da temperatura do ar para a região Nordeste do Brasil. Revista Brasileira de Engenharia Agrícola e Ambiental, v.10, p.140-147, 2006. DOI: 10.1590/S1415-43662006000100021.

COLLIER, R.J.; DAHL, G.E.; VANBAALE, M.J. Major advances associated with environmental effects on dairy cattle. Journal of Dairy Science, v.89, p.1244-1253, 2006. DOI: 10.3168/jds. S0022-0302(06)72193-2.

COUTO, S.K.A.; SOUSA, B.B. de; SILVA, A.M. de A; BENICÍO, T.M.A.; SANTOS, J.R.S. dos. Degradabilidade in situ do rolão 
e farelo de milho em caprinos e ovinos deslanados mantidos em sombra natural e artificial no Semi-árido paraibano. Ciência e Agrotecnologia, v.33, p.1415-1423, 2009. DOI: 10.1590/ S1413-70542009000500031.

DADOS pluviométricos mensais do Nordeste: Estado de Pernambuco. Recife: Sudene, 1990.363p. (Sudene. Pluviometria, 6).

HAHN, G.L. Management and housing of farm animals in hot environments. In: YOUSEF, M.K. (Ed.). Stress physiology in livestock. Boca Raton: CRC Press, 1985. v.2, p.151-174.

MEDEIROS, L.F.D.; VIEIRA, D.H.; OLIVEIRA, C.A. de; MELLO, M.R.B. de; LOPES, P.R.B.; SCHERER, P.O.; FERREIRA, M.C.M. Reações fisiológicas de caprinos das raças Anglo-Nubiana e Saanen mantidos à sombra, ao sol e em ambiente parcialmente sombreado. Boletim da Indústria Animal, v.65, p.7-14, 2008.

MENDES, A.M.P. Índice de conforto térmico e zoneamento bioclimático para ovinos da raça Dorper no Estado de Pernambuco. 2014. 161p. Tese (Doutorado) - Universidade Federal Rural de Pernambuco, Recife.

MILNE, C. The history of the Dorper sheep. Small Ruminant Research, n.36, p.99-102, 2000. DOI: 10.1016/ S0921-4488(99)00154-6.

NAVARINI, F.C.; KLOSOWSKI, E.S.; CAMPOS, A.T.; TEIXEIRA, R. de A.; ALMEIDA, C.P. Conforto térmico de bovinos da raça Nelore a pasto sob diferentes condições de sombreamento e a pleno Sol. Engenharia Agrícola, v.29, p.508-517, 2009. DOI: 10.1590/S0100-69162009000400001.

NEVES, M.L.M.W.; AZEVEDO, M. de; COSTA, L.A.B. da; GUIM, A.; LEITE, A.M.; CHAGAS, J.C. Níveis críticos do índice de conforto térmico para ovinos da raça Santa Inês criados a pasto no Agreste do Estado de Pernambuco. Acta Scientiarum. Animal Sciences, v.31, p.169-175, 2009. DOI: 10.4025/actascianimsci. v31i2.3766.

NORMAIS climatológicas do Brasil: 1961 1990. Brasília: INMET, 2009. 465p.
PIRES, M. de F.A.; SILVA JUNIOR, J.L.C. da; CAMPOS, A.T. de; COSTA, L.C.; NOVAES, L.P. Zoneamento da região Sudeste do Brasil, utilizando o índice de temperatura e umidade. Juiz de Fora: Embrapa Gado de Leite, 2003. 21p. il. (Embrapa Gado de Leite. Boletim de pesquisa e desenvolvimento, 13).

ROBERTO, J.V.B.; SOUZA, B.B. de; SILVA, A.L.N. da; JUSTINIANO, S.V.; FREITAS, M.M.S. Parâmetros hematológicos de caprinos de corte submetidos a diferentes níveis de suplementação no Semi-árido paraibano. Revista Caatinga, v.23, p.127-132, 2010.

SCHOLTZ, M.M.; MCMANUS, C.; LEEUW, K.-J.; LOUVANDINI, H.; SEIXAS, L.; MELO, C.B. de; THEUNISSEN, A.; NESER, F.W.C. The effect of global warming on beef production in developing countries of the southern hemisphere. Natural Science, v.5, p.106-119, 2013. DOI: 10.4236/ns.2013.51A017.

SILVA, R.G. da. Biofísica ambiental: os animais e seu ambiente. Jaboticabal: Funep, 2008, 386p.

SILVA, T. G. F. da; ZOLNIER, S.; MOURA, M.S.B.; SEDIYAMA, G.C.; STEIDLE NETO, A.J.; SILVA JÚNIOR, J.L.C. da. Potencial agroclimático para o cultivo da atemóia (Annona squamosa $\mathrm{L}$. $\mathrm{x}$ Annona cherimola mill.) no Estado da Bahia. Revista Brasileira de Agrometeorologia, v.14, p.261-271, 2006.

STARLING, J.M.C.; SILVA, R.G. da; NEGRÃO, J.A.; MAIA, A.S.C.; BUENO, A.R. Variação estacional dos hormônios tireoideanos e do cortisol em ovinos em ambiente tropical. Revista Brasileira de Zootecnia, v.34, p.2064-2073, 2005. DOI: 10.1590/ S1516-35982005000600032.

THOM, E.C. Cooling degree: day air conditioning, heating, and ventilating. Transactions of the American Society of Heating Refrigeration and Air-Conditioning Engineers, v.55, p.65-72, 1958.

VIANELlO, R.L.; ALAVES, A.R. Meteorologia básica e aplicações. 2.ed. Viçosa: Ed. da UFV, 2012. 460p.

WEST, J.W. Effects of heat-stress on production in dairy cattle. Journal of Dairy Science, v.86, p.2131-2144, 2003. DOI: 10.3168/ jds.S0022-0302(03)73803-X.

Recebido em 5 de abril de 2014 e aprovado em 23 de outubro de 2014 